\title{
Immortalized murine fibroblast cell lines are refractory to reprogramming to pluripotent state
}

\author{
Elena V. Skvortsova ${ }^{1}$, Sergey A. Sinenko ${ }^{1,2}$ and Alexey N. Tomilin ${ }^{1,3}$ \\ ${ }^{1}$ Institute of Cytology, Russian Academy of Sciences, St Petersburg, Russian Federation \\ ${ }^{2}$ Division of Molecular and Radiation Biophysics, B.P. Konstantinov Petersburg Nuclear Physics Institute, NRC "Kurchatov \\ Institute", Orlova Roscha, Gatchina, Russian Federation \\ ${ }^{3}$ St Petersburg State University, St Petersburg, Russian Federation \\ Correspondence to: Sergey A. Sinenko, email: s.sinenko@incras.ru \\ Alexey N. Tomilin, email: a.tomilin@incras.ru
}

Keywords: iPSC; NIH3T3; STO; pluripotency; cell reprogramming

Received: July 25, $2018 \quad$ Accepted: October 06, 2018

Published: October 16, 2018

Copyright: Skvortsova et al. This is an open-access article distributed under the terms of the Creative Commons Attribution License 3.0 (CC BY 3.0), which permits unrestricted use, distribution, and reproduction in any medium, provided the original author and source are credited.

\section{ABSTRACT}

To date different cell types of various mammalian species have been reprogrammed to induced pluripotent stem cells (iPSCs) using Yamanaka's cocktail of transcription factors (Oct4, KIf4, Sox2, and cMyc). It has been shown that several primary human cancer cell lines could be reprogrammed to iPSCs. We sought if immortalized mouse fibroblast cell lines could also be reprogrammed to iPSCs. The approach of generating iPSCs from such cells should be valuable in different experimental settings as it allows clonally derive cell lines carrying mutations whose impact on reprogramming could be next evaluated. Therefore, we investigated reprogramming of widely used immortalized cell lines (NIH3T and STO), as well as of de novo immortalized fibroblast line (tKM) with the use of highly effective lentiviral polycistronic OKSM expression system. Our reprogramming experiments have shown that in contrast to mouse embryonic fibroblasts (MEFs), none of the immortalized cell lines can be reprogrammed to pluripotent state. Contrary to colonies derived from MEFs, those derived from the immortalized cells lines (1) developed much later, (2) contained large round cells, not typical for iPSCs, and ( 3 ) were negative for trusted markers of matured iPSCs, Nanog and SSEA1. Immortalized cell lines NIH3T and STO are known to be mostly aneuploid, whereas tKM population includes cells with normal karyotype, however, neither cell type can be reprogrammed. Thus our data argue that aneuploidy per se is not a reason for the observed refractoriness of mouse immortalized cells to reprogramming to pluripotent state.

\section{INTRODUCTION}

The major breakthrough in understanding mechanisms of maintenance and handling pluripotent stem cells become available after discovery of the method of reprogramming somatic cells to pluripotent state by four transcription factors, or so call Yamanaka's cocktail: Oct4, Sox2, Klf4, and cMyc [1]. The reprogramming is mediated by resetting the epigenome of somatic cells and results in generation of induced pluripotent stem cells (iPSCs). They are functionally and molecularly analogous to embryonic stem cells (ESCs) originated from pre-implantation embryo epiblast $[2,3]$. During reprogramming process, almost all cells go through the initiation phase characterized by the down-regulation of differentiation genes and the activation of early pluripotency factors. However, vast majority of cells remain refractory to reprogramming, and only rare cells go through the second stage, set up stable expression of the core pluripotency network, and become pluripotent $[4,5]$. Although there is significant body of knowledge about molecular mechanisms of cell reprogramming to pluripotent state, yet these aspects remain poorly understood. To date different types of somatic cells were successfully reprogrammed to pluripotent state [6-13]. iPSCs of different mammalian species including primates, 
rodents, ungulates, and felines were generated with use of standard reprogramming technique [14-20]. However there are some differences in a way of applying the reprogramming method to different cell types and cells from different species. For instance, in contrast to mouse fibroblasts, rat fibroblasts can be reprogrammed only in serum-free media conditions [16]. Reprogramming efficiency depends on stochastic equilibrium and levels of expression of pluripotency transcription factors. Recent data support deterministic versus stochastic model of cell reprogramming [21].

To date there were multiple attempts to reprogram malignant cancer cell lines. It was shown that a number of human primary cancer cells lines of different origin could be reprogrammed to pluripotent state [22-27]. However, generation of cancer-derived iPSCs remains a challenging task. The reprogramming inefficiency and relative instability of the cancer-derived iPSCs became the main issues $[28,29]$. On the other hand, referring to the published data, iPSCs have been generated only from few mouse primary cancer cell lines, suggesting that mouse cancer cells are mainly refractory to reprogramming in standard condition [29, 30]. It is known that multiple passages and culture conditions lead to significant abnormalities in chromosome numbers and stability. Efficiency of cell reprogramming significantly decreases at advanced passages of primary cell cultures and in more terminally differentiated cells $[31,32]$. However it has not been yet analyzed and understood how prolonged cultivation leads to refractoriness to the reprogramming. On the other hand, malignant transformed or immortalized cell lines have several advantages over primary cell cultures, such as easy handling, high proliferation rate, and clonogenicity, all are beneficiary in several experimental setups. In particular, use of such cells is beneficial because it would allow to clonally derive mutants which could be subsequently assayed for reprogramming to iPSCs. Here we provide an experimental evidence of inability of immortalized cells, both aneuploid and normal, to be reprogrammed into iPSCs, indicating that aneuploidy is not the cause of such refractoriness.

\section{RESULTS AND DISCUSSION}

\section{OKSM cassette is more efficient than OSKM for cell reprogramming into iPSCs}

To reprogram mouse embryonic fibroblasts, we used two previously developed vectors bearing all four reprogramming transcription factors. The OSKM vector representing single polycistronic vector allowing expressing full-length murine Oct4, Sox2, Klf4, and cMyc by autonomous "self-cleaving" 2A peptides [33]. Another polycistronic vector expressing full-length human Oct4, Klf4, Sox2, and cMyc (OKSM) interspaced with the 2A peptides and IRES sequence was also used [34].
Polycistronic vectors are more efficient in reprogramming and besides, allow to ectopically express one copy of each gene per cell [33]. Almost complete homology between these transcription factors in mammals allows using them for reprogramming of both human and mouse cells. First, we performed reprogramming of MEFs with the use of each of the two lentiviral constructs. We have found that OKSM construct shows about 60 -fold higher reprogramming efficacy $(6 \%)$ vs. OSKM $(0,1 \%)$ (Figure 1). The cause of this dramatic difference in reprogramming efficacy is not clear, given titers of both polycistronic viruses and multiplicity of infection (MOI) are approximately equal, however, it can be assumed that ratios between expression levels of the four transcription factor is critical. For instance, it was shown that efficiency of reprogramming is much higher when levels of expressions of Oct4 and Klf4 significantly exceed those of cMyc and Sox $2[35,36]$. Interesting to note that in comparison to OSKM, transduction of MEFs with OKSM virus led to development of primary or intermediate clones (starting on day 7), consisting of relatively large round-shaped cells (Figure 1, and Supplementary Figure 1 , indicated by arrows). These cells probably represent an intermediate stage during cell reprogramming. It was also obvious that true MEF-derived iPSC clones (at day 14) often positioned as clusters of colonies of different sizes (Figure 1, and Supplementary Figure 1, depicted with arrows). This might indicate that these clusters of clones are likely to derive from one parental cell. In this scenario one single fibroblast is reprogramed to "intermediate" iPSCs colonies with round-shaped cells, and some of these cells are further reprogrammed to bona fide iPSCs, forming the observed clusters of colonies. This is consistent with an observation that fast-cycling cells give increased cell numbers and they likely have certain intrinsic properties, such as epigenetic predisposition to being reprogrammed [21]. Previously, it was reported that OKSM STEMCCA polycistronic cassette was highly efficient in iPSCs generation while the large number of clones induced by this construct displayed lack of Nanog expression [37]. Importantly, we used another OKSM construct [34], which induced a high number of iPSC clones, and all of these clones expressed high levels of Nanog (see below). We have also found that N2B27 $2 \mathrm{i}$ serum-free media is more reproducible and efficient than serum-based media for iPSCs generation (data not shown). The OKSM polycistronic vector and N2B27 $2 \mathrm{i}$ media were selected for further cell reprogramming experiments.

\section{NIH3T3 and STO cells cannot be reprogrammed to iPSCs}

It is often highly desirable to assess roles of genes of interest in reprogramming to iPSCs, applying CRISPR/ Cas9 or more traditional methods of transgenesis to cells prior to reprogramming. However, a vast majority 
of primary cell types used for reprogramming, such as MEFs or blood cells, have limited proliferation potential, and thus, derivation of mutant clones for subsequent iPSC derivation assays is not feasible. On the contrary, immortalized or transformed cells of established cell lines posses basically unlimited clonogenic potential. Therefore, we attempted to reprogram to iPSCs widely used mouse cell lines of fibroblast origin, namely NIH3T3 and STO. To this end, we used the above OKSM polycistronic vector which showed superior reprogramming efficiency. MEFs, NIH3T3, and STO cells were transduced with equal amounts of viruses. Important to note that NIH3T3 and STO cells proliferated significantly faster than MEFs, i.e. $>2.5$ times (Supplementary Table 1). Round-shaped clones have been developed in NIH3T3 and STO cell cultures starting from day 9. Cells within these clones were round and different from regular iPSCs (Figure 2A, indicated by arrows). Majority of those clones were positive for alkaline phosphatase (Figure 2A). Immunostaining for pluripotency markers Nanog and SSEA1 revealed that none of these clones expressed the proteins, which is opposed to MEF-derived iPSC clones (Figure 2B, $2 \mathrm{C}$, see details in Material and Methods). These results suggests that OKSM is able to trigger the process of cell reprogramming, evidenced by developed primary clones, however, the latters fail to further proceed to pluripotent state. Three independent reprogramming experiments showed no signs of iPSC generation from NIH3T3 and STO cells. These cell lines could not be reprogrammed to iPSCs using either OSKM, or mixture of Oct4, Sox2, Klf4, cMyc viruses (Supplementary Figure 2). We also attempted to culture several clones derived from NIH3T3 and STO cells. Expectedly, 15 and 10 selected clones derived from each of these cell lines could not be maintained as

A

OSKM
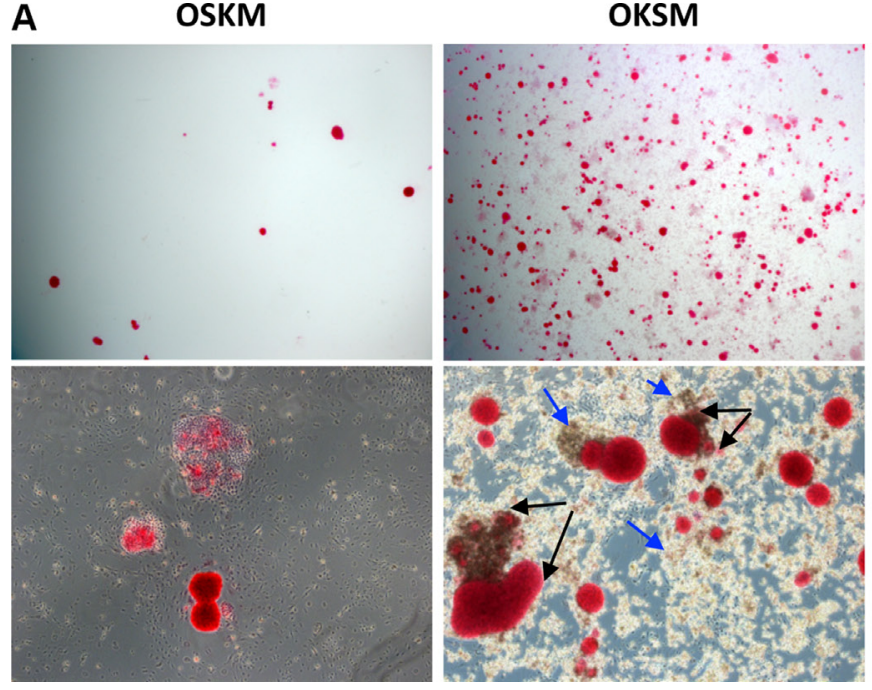

iPSCs in mouse embryonic stem cell media. All these cells showed a typical morphology of differentiated cells that resembled fibroblasts (Supplementary Figure 3). We also observed that mouse cell line OP9, which represents immortalized embryonic bone morrow stromal stem cell origin, cannot be reprogrammed to iPSCs with OKSM (Supplementary Figure 4). It is known that all studied immortalized cell lines have chromosomal abnormalities. Most karyotypically characterized NIH3T3 cell line has $98,8 \%$ aneuploidy where $60 \%$ of cells are tetraploids with numerous chromosomal translocations, including balanced and unbalanced translocations, inverted duplications, deletions, or complex rearrangements [38]. STO and OP9 cell lines are also aneuploids, however, the degree of the karyotype abnormality has not yet been evaluated in details $[39,40]$. Another feature of immortalized cell line is high proliferative index and constitutive activation of signaling pathways mediating high proliferation rates. It is likely that these two features are the major causes of the refractoriness to the cell reprogramming, however, this hypothesis requires further corroboration. Besides, it is likely that there is a significant reduction of $\mathrm{p} 53$ function in immortalized cell lines, however, while loss of p53 is advantageous for iPSC generation from primary cells $[41,42]$, it does not seem to predispose immortalized cells to better reprogramming.

\section{Newly established cell line tKM cannot be reprogrammed to iPSCs}

It is known that long time exploited cell lines such as NIH3T3 and STO accumulate multiple chromosomal abnormalities and evolve dramatically to maintain themselves through numerous passages in culture. We

\section{B}

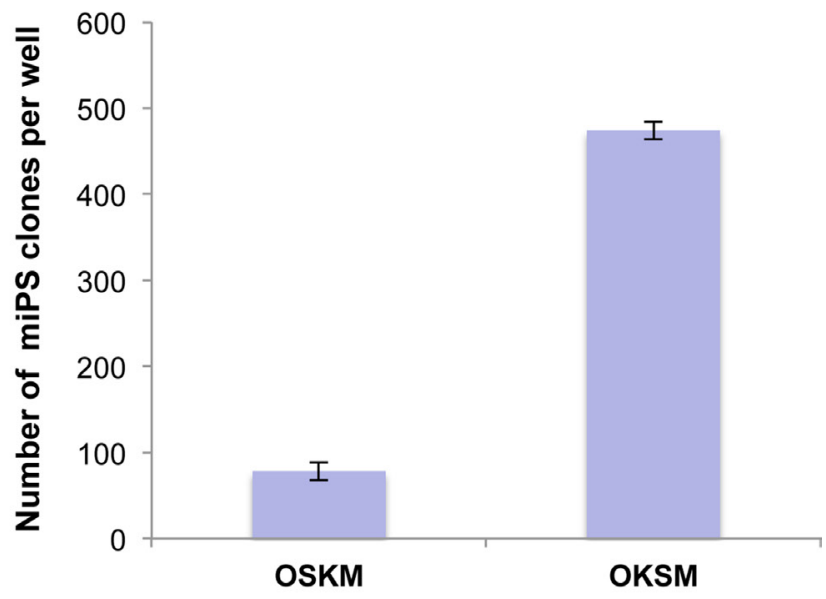

Figure 1: OKSM polycistronic vector is more efficient in generation of iPSCs. (A) iPSC clones revealed by alkaline phosphatase (AP) staining on day 14 following infection with polycistronic lentiviruses OSKM or OKSM; magnifications: 4x - upper images, 10x - lower images. Presumable sister iPSC clones within the clusters indicated by black arrows. Conglomerates of large roundshaped "intermediate" cells indicated by blue arrows. (B) Counts of AP-positive iPSC clones generated by day 14 with the use of OSKM or OKSM cassettes; results are expressed as mean $\pm \mathrm{SD}, n=3$. 
A

A

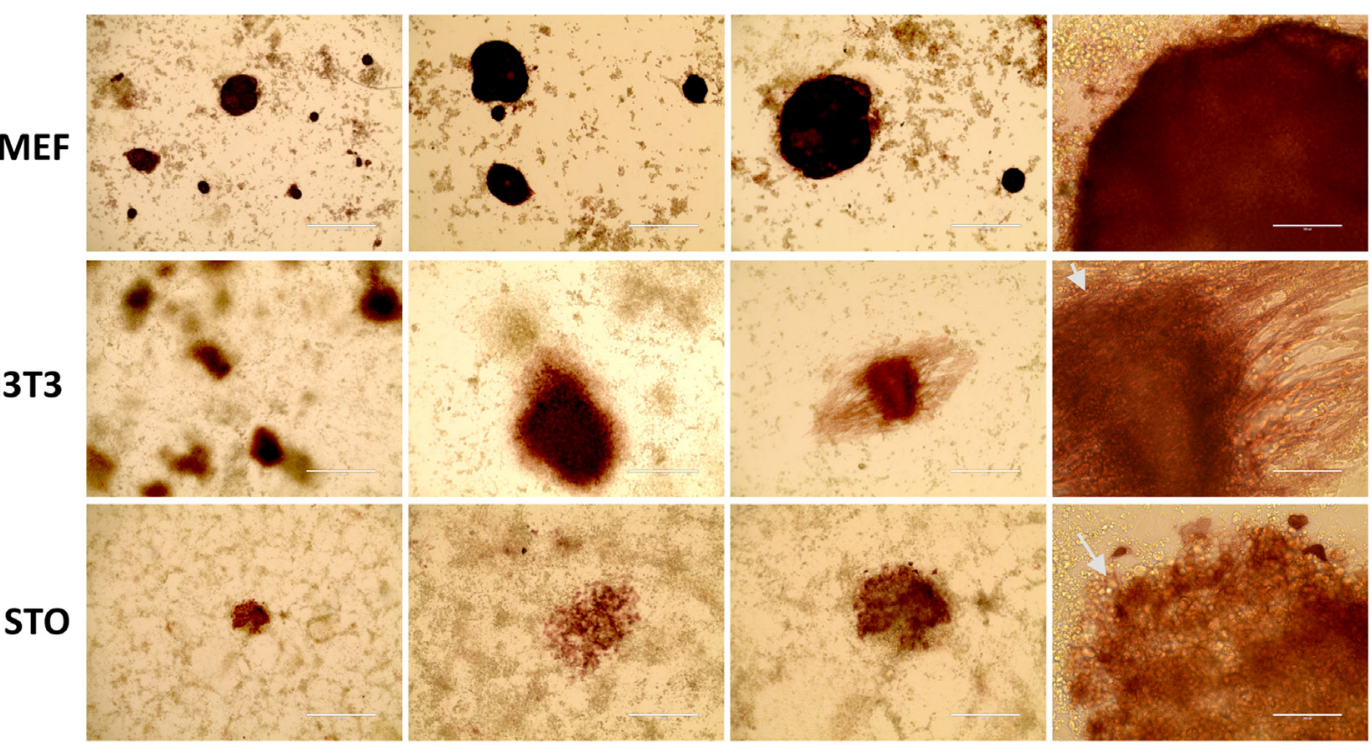

B
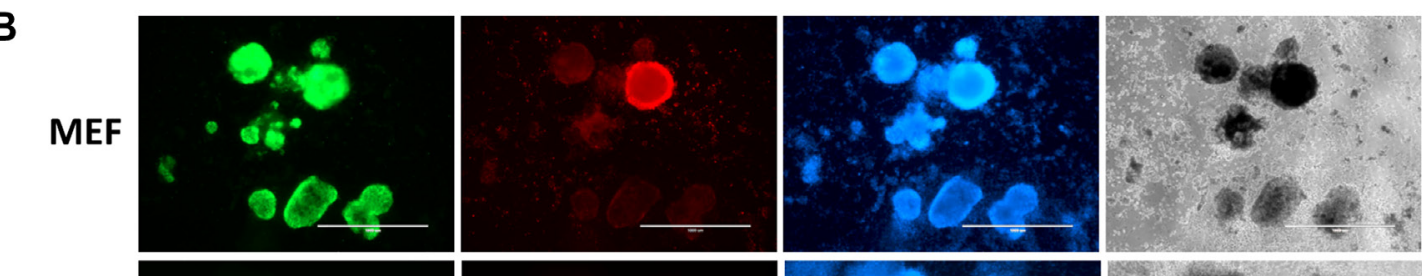

NIH-3T3
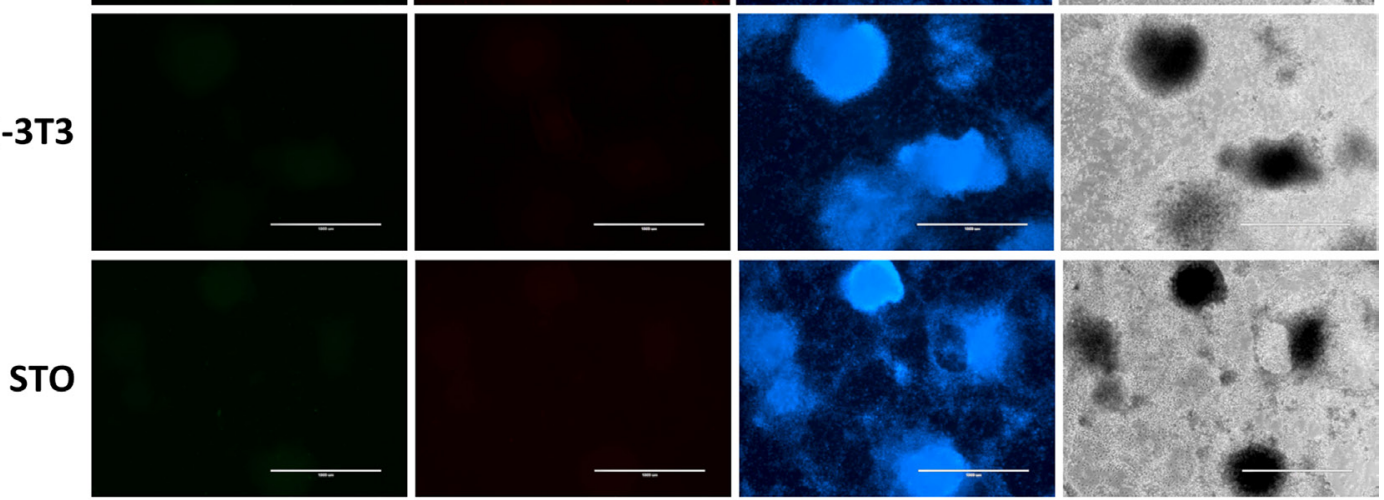

C

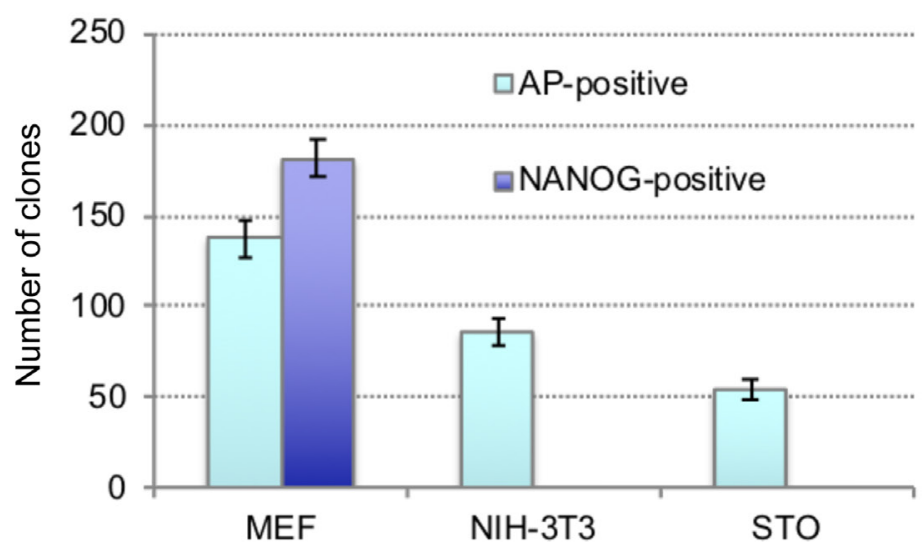

Figure 2: NIH3T3 and STO cells cannot be reprogrammed into iPSCs. (A) Representative images of cell clones derived from MEFs, NIH3T3, and STO cells, as revealed by AP-staining on day 14 after OKSM lentivirus infection; large round shaped cells indicated by arrows. (B) Immunostaining of the colonies on day 14 after OKSM induction revealed lack of Nanog (green) and SSEA1 (red) expression in colonies derived from NIH3T3 and STO cells, contrary to those derived from MEFs; cells were counterstained with DAPI (blue) (C) Counts of AP-positive and Nanog-positive cell colonies derived from MEFs, NIH3T3, and STO cells generated on day 14 after OKSM lentivirus infection; results are expressed as mean $\pm \mathrm{SD}, n=2$. 
asked whether immortalized cells with normal karyotype can be reprogrammed to pluripotency. To this end, we first infected MEFs with lentiviruses encoding Klf4, cMyc, and the repressor tT-KRAB, then selected for blasticidin S-resistant clones in the presence of Dox (to keep tT-KRAB away from repressing the Klf4, cMyc viruses). One of the picked clones, referred hereafter to as tKM, could be subsequently passaged in the absence of Dox, which ensured lack of the exogenous Klf4 and cMyc expression. Karyotypic analysis revealed that after multiple passages ( $>18$ ) $56 \%$ of tKM cells preserved normal karyotype i.e. 40 chromosomes (Supplementary Figure 5 and Supplementary Table 2). Similar to NIH3T3 and STO, tKM cells infected with OKSM at passage 19 could give rise to some AP-positive colonies, however, all of them were negative for Nanog and SSEA1. Besides, these colonies were significantly larger than MEF-derived iPSC colonies, they became rather loose, easily detached from plate surface (Figure 3). Also, after picking the tKM-derived colonies, they could not be further maintained and passaged like iPSC in embryonic stem cell media. Thus, tKM fibroblasts, which have mostly normal ploidy, are refractory to reprogramming, like mostly aneuploid NIH3T3 and STO cells. This result suggests that aneuploidy per se is not the factor that counteracts OKSMmediated reprogramming into iPSCs.

Several other reports also showed refractoriness of mouse cancerous cell lines to the reprogramming $[3,43]$. At the same time, it was shown that primary mouse carcinoma cells and malignant melanoma cell line remain amenable to reprogramming to iPSCs [10, 29, 30]. Also it was shown that immortalized mouse fibroblast cells $\mathrm{m} 5 \mathrm{~S}$ can be efficiently reprogrammed via cell fusion with ESCs [44]. The two situations, however, cannot be compared one-to-one, because mechanism of cell fusionbased reprogramming might be significantly different from reprogramming driven by OKSM [21, 44, 45].

What could be the factors serving as roadblocks on the way immortalized cell being reprogrammed into iPSC? It is known that an abnormal cell signaling, for instance, activation of MAPK (p38) [46-48], TGF $\beta$ [49, 50], or Hippo/LATS2 [51] pathways strongly suppress the iPSC generation. From the other side, it was shown that cell immortality is a crucial and rate-limiting step towards the establishment of a pluripotent state in somatic cells. Such cells with low p19 protein levels as well as immortal fibroblasts deficient in components of p53 pathway develop iPSCs colonies much faster and almost each of
A

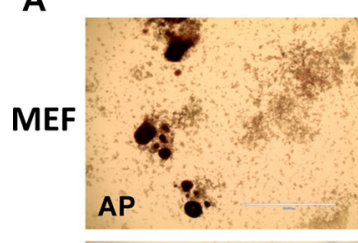

KM

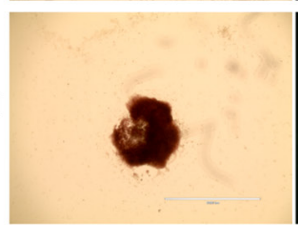

B
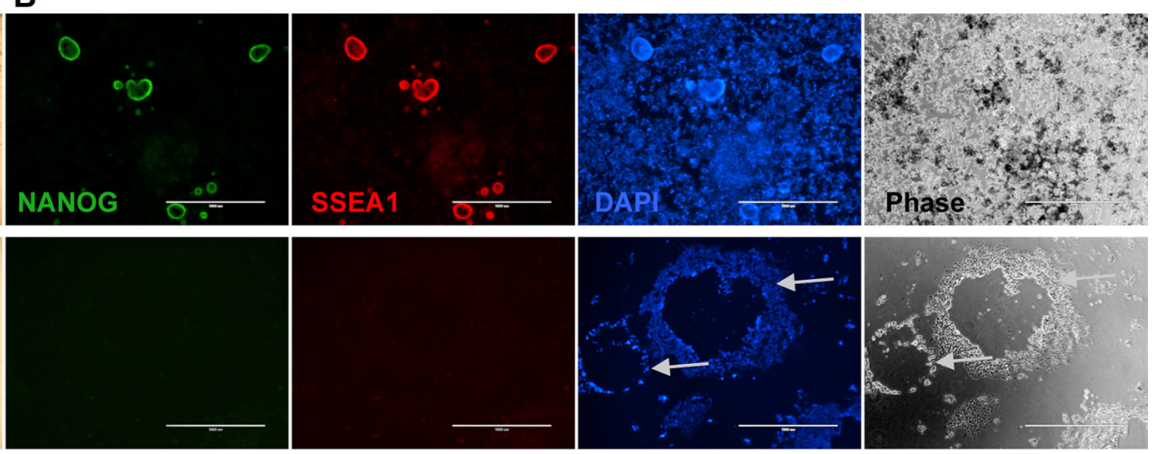

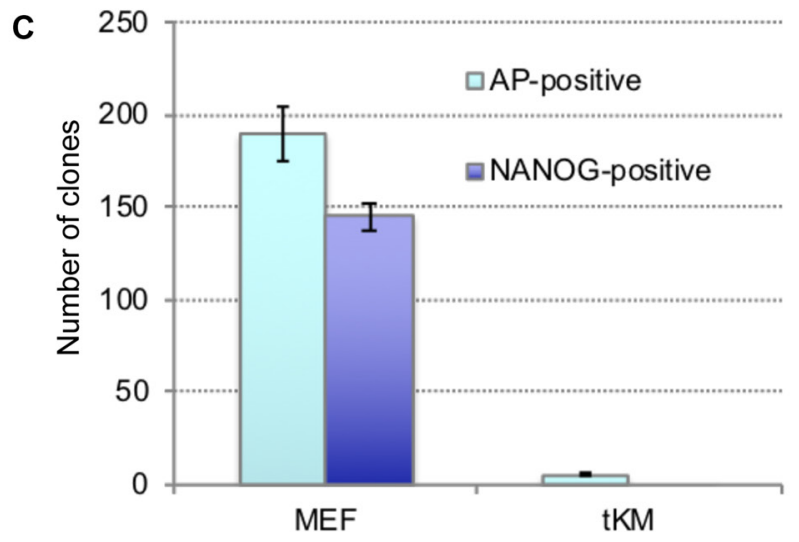

Figure 3: De novo immortalized fibroblasts (tKM cells) cannot be reprogrammed to iPSCs. Representative images of cell colonies derived from tKM cells and, for control, MEFs, revealed by AP-staining (A) or by immunostaining for Nanog (green) and SSEA1 (red) (B) on day 14 after OKSM lentivirus infection. Cells were counterstained with DAPI (blue). tKM-derived clones are rare, notably larger, and have very low adhesion to plastic surface, compared to MEF-derived clones. (C) Counts of AP- and Nanog-positive cell colonies derived from MEFs and tKM cell; results are expressed as mean $\pm \mathrm{SD}, n=2$. 
these somatic cells have the potential to form iPSCs [52]. Activation of p16 (Ink4a) and p19 (Arf) promotes p53-p21 signaling, inhibiting iPSC generation [41, 42]. Activation of AMP-activated protein kinase (AMPK) provides a metabolic barrier to reprogramming somatic cells into stem cells [48, 53, 54]. Another relevant example is spermatogonial stem cells (SSCs) which are refractory to reprogramming to pluripotency [55]. Compared to ESCs, SSCs express lower levels of Oct4 and Sox2, and higher levels of Klf4 and cMyc. Deregulated expression of these pluripotency genes triggered by ectopic overexpression of OSKM and abnormal epigenetic regulation of specific regulatory elements involved in reprogramming might be the cause of the refractoriness of these cells to iPSC reprogramming. Moreover, it was shown that p53 pathway does not contribute to the refractoriness of SSCs to reprogramming [55]. It was also shown that naked mole rat (NMR) fibroblasts have drastically reduced propensity for reprogramming, compared to mouse fibroblasts. Inactivation of $\mathrm{Rb}$ alone, but not of $\mathrm{p} 53$, or expression of SV40 LT-antigen was sufficient to improve reprogramming efficiency. Compared to mouse, NMR had higher levels of repressive H3K27 methylation marks and lower levels of activating H3K27 acetylation marks, indicative of a more stable epigenome that resisted cell reprogramming [15].

Important to note that human primary cancer cell lines could be reprogrammed to iPSCs more efficiently than mouse ones [22, 26, 29, 56-60]. Several studies have reported generation of iPSCs from primary chronic myeloid leukemias, MLL-AF4-overexpressing hematopoietic stem cells/B progenitors, indicating that B-cell origin and leukemic fusion gene were not reprogramming barriers $[28,58,61]$. It still remains an unresolved question whether success of reprogramming depends only on the presence of so call "elite" cells, or it can be reached by any cell [21, 62]. Resent studies applying cellular barcoding technique indicate deterministic versus stochastic model of reprogramming [21]. The authors also showed that a population of fastcycling cells was characterized by a high reprogramming potential. Although the investigated cell lines have high proliferation rate, the rates of generation of pseudoiPSC clones from this cells are not higher than for MEFs (Supplementary Table 1). It is assumed that reprogramming potential is inherent to particular cell type and could be passed on through cell division. It is well known that less differentiated somatic precursor cells are more efficiently reprogrammed to pluripotency [63]. One can assume that long time maintained cell lines are evolved in more differentiated cell state that are refractory to reprogramming. Our experiments have shown that while the initial step of reprogramming triggered by OKSM occurs in NIH3T3, STO, and tKM cells, they could not be further reprogrammed to pluripotent state. Previous reports indicated that chromosomal abnormalities, and aneuploidy, as well as altered cell signaling associated with the cancer cell lines is a cause of the inability to be reprogrammed to pluripotent state $[57,64,65]$. Our analysis indicates that among these features aneuploidy of the studied murine cell lines is unlikely to be a roadblock to pluripotency reprogramming. Further analysis of mouse cancer cell lines in terms of pluripotency reprogramming will help to decipher the exact mechanism of their resistance to this process.

\section{MATERIALS AND METHODS}

\section{Lentiviruses}

The LVTHM-T7-Oct4, -Sox2, -cMyc, and -K1f4 constructs were described elsewhere (Liskovykh et al., 2011). LV-tTR-KRAB-iresBsd was derived from LV-tTRKRAB-iresDsRed [66] by replacing the DsRed sequence with blasticidin $\mathrm{S}$ resistance gene. Other constructs were kindly provided by different labs: LV-tTR-KRAB-dsRed, pMD2.G, and psPAX2 [66], HAGE2-TetO-miniCMVhOct4-F2A-hKlf4-IRES-hSox2-E2A-hcMyc-W-loxP (OKSM) [67], tetO-FUW-OSKM (OSKM, Addgene plasmid \#20321) and FUW-M2rtTA (M2rtTA, Addgene plasmid \# 20342) [33]. Lentiviruses were packaged in $293 \mathrm{~T}$ cells using polyethylenimine hydrochloride (PEI $40 \mathrm{kDa}, 40 \mu \mathrm{g}$ ) as a transfection method [68]. Lentivirus particles in cell culture supernatant were collected, concentrated to $5-10 \times 10^{6} \mathrm{TU} / \mathrm{ml}$ as described elsewhere $[16,66,69,70]$.

\section{Cell lines}

Mouse embryonic fibroblast derived cell lines, NIH3T3 and STO, were obtained from the Russian Cell Culture Collection (Institute of Cytology RAS, St Petersburg, Russia) where they had been karyotyped, as follows: 65-73 chromosomes (75-90\% of cells), $1-2 \%$ microchromosomes, and $1.2 \%$ of polyploid cells for NIH3T3, 55-65 chromosomes, 1-2 microchromosomes, and $7.0 \%$ of polyploid cells for STO [38, 40]. Embryonic bone morrow stromal stem cell line OP9 were obtained from ATCC (CRL2749). Murine embryonic fibroblasts (MEFs), prepared from 13.5-14.5 dpc C57Bl6 mouse embryos [16], were infected with the lentiviruses LVTHMT7-Klf4, LVTHM-T7-cMyc, and pLV-tT-KRAB-iresBsd, then cultured for 12 days in presence of Doxycycline (Dox, $5 \mu \mathrm{g} / \mathrm{ml}$ ) and blasticidin $\mathrm{S}(2 \mu \mathrm{g} / \mathrm{ml})$. Several resistant colonies were picked, cultured for 2-3 passages in the same medium, then cultured for several passages in Dox-free medium. One clone, referred to as tKM, which showed robust proliferation in the absence of Dox was considered immortalized and thus, was proceeded to iPSC derivation experiments. 


\section{Reprogramming mouse fibroblasts with OKSM or OSKM/M2rtTA}

MEFs, NIH3T3, and STO cells were grown in standard MEF media containing DMEM media (Biolot, Russia), 10\% FBS (HyClone), $100 \mathrm{U} / \mathrm{ml}$ penicillin, $100 \mu \mathrm{g} / \mathrm{ml}$ streptomycin, and $2 \mathrm{mM}$ l-glutamine (Gibco). Cells were treated against mycoplasma by culturing with $10 \mu \mathrm{g} / \mathrm{ml}$ ciprofloxacin (Myco-3, AppliChem, EU) or $10-25 \mu \mathrm{g} / \mathrm{ml}$ Plasmocin (Invivogen) in media for 1-2 passage. Monitoring mycoplasma was routinely performed by PCR. Cell cultures were maintained at $5 \% \mathrm{CO}_{2}$ at $37^{\circ} \mathrm{C}$. Cells were seeded $\left(30 \times 10^{3}\right.$ cells per well) on $0.1 \%$ gelatin-coated 24-well plate in the MEF medium. Next day media was replaced with $200 \mu \mathrm{l}$ of Opti-MEM media (Gibco) containing mixture of lentiviruses (MOI $=2-5$ for each): (1) M2rtTA + pHAGE2-OKSM, (2) tetO- OSKM + M2rtTA, or (3) LVTHM-T7-Oct4, -Sox2, -Klf4, -cMyc (see Lentiviruses for details). Cells were incubated with the virus mixtures for 3-4 hrs, then $200 \mu \mathrm{l}$ of Opti-MEM were added and incubation was continued overnight. Next day media was changed to MEF media containing $3 \mu \mathrm{g} / \mathrm{ml}$ Dox. Media was changed to fresh every day and on the 3rd day cells were trypsinized and seeded onto wells of 12- or 6- well plates pre-coated with gelatin and feeder cells (mitomycin C-treated MEFs) and cultured in N2B27 2i media containing standard N2B27 medium (Gibco) supplemented with $3 \mu \mathrm{M}$ CHIR-99021 (Axon Medchem) $1 \mu \mathrm{M}$ PD-0325901 (Axon Medchem), recombinant hLIF $\left(5 \mathrm{ng} / \mathrm{ml}\right.$ ), and $3 \mu \mathrm{g} / \mathrm{ml}$ Dox at $37^{\circ} \mathrm{C}$ in a standard $\mathrm{CO}_{2}$ incubator. Medium was changed every next or second day. Clones became visible on day 9, and on day 14-15 they were fixed and proceeded for immunostaining. To ensure reproducibility, all reprogramming experiments were repeated at least twice, and results from one of these experiments were presented on each figure (Figures 1-3). Standard deviations between repeats (wells repeats) within the particular experiment are shown on the diagrams. We noticed that in some experiments with MEF reprogramming the number of Nanog-positive clones exceeded the number of AP-positive clones (Figure 2C). This variability in clone counts was primarily because often Nanog immunostaining revealed multiple clones within clone cluster that was recognized as one large AP-positive clone. We represented both cases of the experiments on Figures 2C and 3C.

\section{Immunostaining}

Mouse iPSCs colonies growing on culture plates were fixed with $4 \%$ paraformaldehyde (PFA) in PBS (10 min, at room temperature), washed with PBS and treated for 30 min with blocking solution: 1\% BSA, $2 \%$ non-immune sheep serum, $0.1 \%$ Tween- 20 in PBS. Fixed cells were incubated with antibodies to mouse Nanog (Bethyl) or Anti-SSEA1 (Developmental Studies Hybridoma Bank), followed by corresponding secondary antibodies conjugated with $\mathrm{Cy}-3$ or FITC (Jackson ImmunoResearch). Afterwards, wells were washed in $0.1 \%$ Tween $20-P B S$, counterstained with DAPI, and embedded under coverslips into an anti-fading media.

\section{Alkaline phosphatase staining}

Mouse iPSC colonies were fixed with PFA and stained for alkaline phosphatase (AP) as described [16] with some minor modifications. PFA-fixed clones were washed in PBS and $25 \mathrm{mM}$ Tris-maleate buffer (pH 9.0) and then incubated with the substrate mixture containing Tris-maleate buffer (pH 9.0), $4 \mathrm{mM} \mathrm{MgCl}_{2}, 0.2 \mu \mathrm{g} / \mathrm{ml}$ 1-Naphthyl phosphate disodium salt (Sigma), and 0,5 $\mu \mathrm{g} / \mathrm{ml}$ Fast Red TR Salt (Sigma), or SigmaFast Fast Red TR/Naphthol AS-MX Tablets (Sigma-Aldrich). The reaction was stopped by washing with PBS.

\section{Ethics statement}

All animal studies were performed in accordance with the relevant guidance and regulations from the Interinstitutional Bioethical Committee of the Institute of Cytology of the Russian Academy of Sciences, Saint Petersburg, Russia.

\section{ACKNOWLEDGMENTS AND FUNDING}

We thank Darrell N. Kotton and Gustavo Mostoslavsky for sharing pHAGE2-OKSM construct, and Didier Trono for LVTHM, LV-tT-KRAB-DsRed, pMD2.G, and psPax 2 plasmids. This work was mainly supported by the he Russian Science Foundation grant No. 14-5000068, part of DNA construction work was supported by Russian Foundation for Basic Research (RFBR) grant No. 17-00-00324.

\section{CONFLICTS OF INTEREST}

None.

\section{REFERENCES}

1. Takahashi K, Yamanaka S. Induction of pluripotent stem cells from mouse embryonic and adult fibroblast cultures by defined factors. Cell. 2006; 126:663-76. https://doi. org/10.1016/j.cell.2006.07.024.

2. Chin MH, Mason MJ, Xie W, Volinia S, Singer M, Peterson C, Ambartsumyan G, Aimiuwu O, Richter L, Zhang J, Khvorostov I, Ott V, Grunstein M, et al. Induced pluripotent stem cells and embryonic stem cells are distinguished by gene expression signatures. Cell Stem Cell. 2009; 5:111-23. https://doi.org/10.1016/j.stem.2009.06.008.

3. Boué S, Paramonov I, Barrero MJ, Izpisúa Belmonte JC. Analysis of human and mouse reprogramming of somatic 
cells to induced pluripotent stem cells. What is in the plate? PLoS One. 2010; 5:e12664. https://doi.org/10.1371/journal. pone. 0012664 .

4. Stadtfeld M, Maherali N, Breault DT, Hochedlinger K. Defining molecular cornerstones during fibroblast to iPS cell reprogramming in mouse. Cell Stem Cell. 2008; 2:230-40. https://doi.org/10.1016/j.stem.2008.02.001.

5. Polo JM, Anderssen E, Walsh RM, Schwarz BA, Nefzger CM, Lim SM, Borkent M, Apostolou E, Alaei S, Cloutier J, BarNur O, Cheloufi S, Stadtfeld M, et al. A molecular roadmap of reprogramming somatic cells into iPS cells. Cell. 2012; 151:1617-32. https://doi.org/10.1016/j.cell.2012.11.039.

6. Stadtfeld M, Brennand K, Hochedlinger K. Reprogramming of pancreatic beta cells into induced pluripotent stem cells. Curr Biol. 2008; 18:890-94. https://doi.org/10.1016/j. cub.2008.05.010.

7. Bueno C, Sardina JL, Di Stefano B, Romero-Moya D, Muñoz-López A, Ariza L, Chillón MC, Balanzategui A, Castaño J, Herreros A, Fraga MF, Fernández A, Granada I, et al. Reprogramming human $\mathrm{B}$ cells into induced pluripotent stem cells and its enhancement by $\mathrm{C} / \mathrm{EBP} \alpha$. Leukemia. 2016; 30:674-82. https://doi.org/10.1038/leu.2015.294.

8. Eminli S, Utikal J, Arnold K, Jaenisch R, Hochedlinger $\mathrm{K}$. Reprogramming of neural progenitor cells into induced pluripotent stem cells in the absence of exogenous Sox2 expression. Stem Cells. 2008; 26:2467-74. https://doi. org/10.1634/stemcells.2008-0317.

9. Aoi T, Yae K, Nakagawa M, Ichisaka T, Okita K, Takahashi K, Chiba T, Yamanaka S. Generation of pluripotent stem cells from adult mouse liver and stomach cells. Science. 2008; 321:699-702. https://doi.org/10.1126/science.1154884.

10. Utikal J, Maherali N, Kulalert W, Hochedlinger K. Sox2 is dispensable for the reprogramming of melanocytes and melanoma cells into induced pluripotent stem cells. J Cell Sci. 2009; 122:3502-10. https://doi.org/10.1242/jcs.054783.

11. Hanna J, Markoulaki S, Schorderet P, Carey BW, Beard C, Wernig M, Creyghton MP, Steine EJ, Cassady JP, Foreman R, Lengner CJ, Dausman JA, Jaenisch R. Direct reprogramming of terminally differentiated mature $B$ lymphocytes to pluripotency. Cell. 2008; 133:250-64. https://doi.org/10.1016/j.cell.2008.03.028.

12. Zhu Y, Liang Y, Zhu H, Lian C, Wang L, Wang Y, Gu H, Zhou G, Yu X. The generation and functional characterization of induced pluripotent stem cells from human intervertebral disc nucleus pulposus cells. Oncotarget. 2017; 8:42700-11. https://doi.org/10.18632/oncotarget.17446.

13. Shutova MV, Bogomazova AN, Lagarkova MA, Kiselev SL. Generation and characterization of human induced pluripotent stem cells. Acta Naturae. 2009; 1:91-92.

14. Esteban MA, Xu J, Yang J, Peng M, Qin D, Li W, Jiang Z, Chen J, Deng K, Zhong M, Cai J, Lai L, Pei D. Generation of induced pluripotent stem cell lines from Tibetan miniature pig. J Biol Chem. 2009; 284:17634-40. https://doi.org/10.1074/jbc.M109.008938.
15. Tan L, Ke Z, Tombline G, Macoretta N, Hayes K, Tian X, Lv R, Ablaeva J, Gilbert M, Bhanu NV, Yuan ZF, Garcia BA, Shi YG, et al. Naked Mole Rat Cells Have a Stable Epigenome that Resists iPSC Reprogramming. Stem Cell Reports. 2017; 9:1721-34. https://doi.org/10.1016/j. stemcr.2017.10.001.

16. Liskovykh M, Chuykin I, Ranjan A, Safina D, Popova E, Tolkunova E, Mosienko V, Minina JM, Zhdanova NS, Mullins JJ, Bader M, Alenina N, Tomilin A. Derivation, characterization, and stable transfection of induced pluripotent stem cells from Fischer344 rats. PLoS One. 2011; 6:e27345. https://doi.org/10.1371/journal.pone.0027345.

17. Shi Y, Desponts C, Do JT, Hahm HS, Schöler HR, Ding S. Induction of pluripotent stem cells from mouse embryonic fibroblasts by Oct4 and Klf4 with smallmolecule compounds. Cell Stem Cell. 2008; 3:568-74. https://doi.org/10.1016/j.stem.2008.10.004.

18. Shimada H, Nakada A, Hashimoto Y, Shigeno K, Shionoya Y, Nakamura T. Generation of canine induced pluripotent stem cells by retroviral transduction and chemical inhibitors. Mol Reprod Dev. 2010; 77:2. https://doi.org/10.1002/mrd.21117.

19. Zhong B, Trobridge GD, Zhang X, Watts KL, Ramakrishnan A, Wohlfahrt M, Adair JE, Kiem HP. Efficient generation of nonhuman primate induced pluripotent stem cells. Stem Cells Dev. 2011; 20:795-807. https://doi.org/10.1089/ scd.2010.0343.

20. Menzorov AG, Matveeva NM, Markakis MN, Fishman VS, Christensen K, Khabarova AA, Pristyazhnyuk IE, Kizilova EA, Cirera S, Anistoroaei R, Serov OL. Comparison of American mink embryonic stem and induced pluripotent stem cell transcriptomes. BMC Genomics. 2015; 16:S6. https://doi.org/10.1186/1471-2164-16-S13-S6.

21. Yunusova AM, Fishman VS, Vasiliev GV, Battulin NR. Deterministic versus stochastic model of reprogramming: new evidence from cellular barcoding technique. Open Biol. 2017; 7:160311. https://doi.org/10.1098/rsob.160311.

22. Kim J, Zaret KS. Reprogramming of human cancer cells to pluripotency for models of cancer progression. EMBO J. 2015; 34:739-47. https://doi.org/10.15252/embj.201490736.

23. Miyoshi N, Ishii H, Nagai K, Hoshino H, Mimori K, Tanaka F, Nagano H, Sekimoto M, Doki Y, Mori M. Defined factors induce reprogramming of gastrointestinal cancer cells. Proc Natl Acad Sci USA. 2010; 107:40-45. https://doi.org/10.1073/pnas.0912407107.

24. Yilmazer Aktuna A. Tendency of K562 chronic myeloid leukemia cells towards cell reprogramming. Turk J Haematol. 2018 May 21. [Epub ahead of print] https://doi. org/10.4274/tjh.2018.0106.

25. Kumano K, Arai S, Hosoi M, Taoka K, Takayama N, Otsu M, Nagae G, Ueda K, Nakazaki K, Kamikubo Y, Eto K, Aburatani H, Nakauchi H, Kurokawa M. Generation of induced pluripotent stem cells from primary chronic myelogenous leukemia patient samples. Blood. 2012; 119:6234-42. https://doi.org/10.1182/blood-2011-07-367441. 
26. Carette JE, Pruszak J, Varadarajan M, Blomen VA, Gokhale S, Camargo FD, Wernig M, Jaenisch R, Brummelkamp TR. Generation of iPSCs from cultured human malignant cells. Blood. 2010; 115:4039-42. https://doi.org/10.1182/ blood-2009-07-231845.

27. Dewi D, Ishii H, Haraguchi N, Nishikawa S, Kano Y, Fukusumi T, Ohta K, Miyazaki S, Ozaki M, Sakai D, Satoh T, Nagano H, Doki Y, Mori M. Reprogramming of gastrointestinal cancer cells. Cancer Sci. 2012; 103:393-99. https://doi.org/10.1111/j.1349-7006.2011.02184.x.

28. Muñoz-López A, Romero-Moya D, Prieto C, RamosMejía V, Agraz-Doblas A, Varela I, Buschbeck M, Palau A, Carvajal-Vergara X, Giorgetti A, Ford A, Lako M, Granada I, et al. Development Refractoriness of MLL-Rearranged Human B Cell Acute Leukemias to Reprogramming into Pluripotency. Stem Cell Reports. 2016; 7:602-18. https://doi.org/10.1016/j.stemcr.2016.08.013.

29. Zhao H, Davies TJ, Ning J, Chang Y, Sachamitr P, Sattler S, Fairchild PJ, Huang FP. A highly optimized protocol for reprogramming cancer cells to pluripotency using nonviral plasmid vectors. Cell Reprogram. 2015; 17:7-18. https://doi.org/10.1089/cell.2014.0046.

30. Lin FK, Chui YL. Generation of induced pluripotent stem cells from mouse cancer cells. Cancer Biother Radiopharm. 2012; 27:694-700. https://doi.org/10.1089/cbr.2012.1227.

31. Polo JM, Liu S, Figueroa ME, Kulalert W, Eminli S, Tan KY, Apostolou E, Stadtfeld M, Li Y, Shioda T, Natesan S, Wagers AJ, Melnick A, et al. Cell type of origin influences the molecular and functional properties of mouse induced pluripotent stem cells. Nat Biotechnol. 2010; 28:848-55. https://doi.org/10.1038/nbt.1667.

32. Eminli S, Foudi A, Stadtfeld M, Maherali N, Ahfeldt T, Mostoslavsky G, Hock H, Hochedlinger K. Differentiation stage determines potential of hematopoietic cells for reprogramming into induced pluripotent stem cells. Nat Genet. 2009; 41:968-76. https://doi.org/10.1038/ng.428.

33. Carey BW, Markoulaki S, Hanna J, Saha K, Gao Q, Mitalipova M, Jaenisch R. Reprogramming of murine and human somatic cells using a single polycistronic vector. Proc Natl Acad Sci USA. 2009; 106:157-62. https://doi.org/10.1073/pnas.0811426106.

34. Sommer CA, Stadtfeld M, Murphy GJ, Hochedlinger K, Kotton DN, Mostoslavsky G. Induced pluripotent stem cell generation using a single lentiviral stem cell cassette. Stem Cells. 2009; 27:543-49. https://doi.org/10.1634/ stemcells.2008-1075.

35. Carey BW, Markoulaki S, Beard C, Hanna J, Jaenisch R. Single-gene transgenic mouse strains for reprogramming adult somatic cells. Nat Methods. 2010; 7:56-59. https://doi.org/10.1038/nmeth.1410.

36. Papapetrou EP, Tomishima MJ, Chambers SM, Mica Y, Reed E, Menon J, Tabar V, Mo Q, Studer L, Sadelain M. Stoichiometric and temporal requirements of Oct4, Sox2, Klf4, and c-Myc expression for efficient human iPSC induction and differentiation. Proc Natl Acad Sci USA. 2009; 106:12759-64. https://doi.org/10.1073/pnas.0904825106.

37. Chantzoura E, Skylaki S, Menendez S, Kim SI, Johnsson A, Linnarsson S, Woltjen K, Chambers I, Kaji K. Reprogramming Roadblocks Are System Dependent. Stem Cell Reports. 2015; 5:350-64. https://doi.org/10.1016/j. stemcr.2015.07.007.

38. Leibiger C, Kosyakova N, Mkrtchyan H, Glei M, Trifonov $\mathrm{V}$, Liehr T. First molecular cytogenetic high resolution characterization of the NIH $3 \mathrm{~T} 3$ cell line by murine multicolor banding. J Histochem Cytochem. 2013; 61:30612. https://doi.org/10.1369/0022155413476868.

39. Gao J, Yan XL, Li R, Liu Y, He W, Sun S, Zhang Y, Liu B, Xiong J, Mao N. Characterization of OP9 as authentic mesenchymal stem cell line. J Genet Genomics. 2010; 37:475-82. https://doi.org/10.1016/S1673-8527(09)60067-9.

40. Pinaev GP, Poljanskaya GG. Establishment and development of the russian collection of human, animals and plants cell cultures. Cell Cultures Information Bulletin. 2010.

41. Kawamura T, Suzuki J, Wang YV, Menendez S, Morera LB, Raya A, Wahl GM, Izpisúa Belmonte JC. Linking the p53 tumour suppressor pathway to somatic cell reprogramming. Nature. 2009; 460:1140-44. https://doi.org/10.1038/ nature 08311 .

42. Hong H, Takahashi K, Ichisaka T, Aoi T, Kanagawa O, Nakagawa M, Okita K, Yamanaka S. Suppression of induced pluripotent stem cell generation by the p53-p21 pathway. Nature. 2009; 460:1132-35. https://doi. org/10.1038/nature08235.

43. Câmara DA, Mambelli LI, Porcacchia AS, Kerkis I. Advances and Challenges on Cancer Cells Reprogramming Using Induced Pluripotent Stem Cells Technologies. J Cancer. 2016; 7:2296-303. https://doi.org/10.7150/jca.16629.

44. Matveeva NM, Fishman VS, Zakharova IS, Shevchenko AI, Pristyazhnyuk IE, Menzorov AG, Serov OL. Alternative dominance of the parental genomes in hybrid cells generated through the fusion of mouse embryonic stem cells with fibroblasts. Sci Rep. 2017; 7:18094. https://doi.org/10.1038/s41598-017-18352-4.

45. Sullivan S, Pells S, Hooper M, Gallagher E, McWhir J. Nuclear reprogramming of somatic cells by embryonic stem cells is affected by cell cycle stage. Cloning Stem Cells. 2006; 8:174-88. https://doi.org/10.1089/clo.2006.8.174.

46. $\mathrm{Li} \mathrm{Z}$, Rana TM. A kinase inhibitor screen identifies small-molecule enhancers of reprogramming and iPS cell generation. Nat Commun. 2012; 3:1085. https://doi. org/10.1038/ncomms2059.

47. Silva J, Barrandon O, Nichols J, Kawaguchi J, Theunissen TW, Smith A. Promotion of reprogramming to ground state pluripotency by signal inhibition. PLoS Biol. 2008; 6:e253. https://doi.org/10.1371/journal.pbio.0060253.

48. Makarev E, Fortney K, Litovchenko M, Braunewell KH, Zhavoronkov A, Atala A. Quantifying signaling pathway activation to monitor the quality of induced pluripotent 
stem cells. Oncotarget. 2015; 6:23204-12. https://doi. org/10.18632/oncotarget.4673.

49. Thiery JP, Sleeman JP. Complex networks orchestrate epithelial-mesenchymal transitions. Nat Rev Mol Cell Biol. 2006; 7:131-42. https://doi.org/10.1038/nrm1835.

50. Maherali N, Hochedlinger K. Tgfbeta signal inhibition cooperates in the induction of iPSCs and replaces Sox2 and cMyc. Curr Biol. 2009; 19:1718-23. https://doi. org/10.1016/j.cub.2009.08.025.

51. Qin H, Blaschke K, Wei G, Ohi Y, Blouin L, Qi Z, Yu J, Yeh RF, Hebrok M, Ramalho-Santos M. Transcriptional analysis of pluripotency reveals the Hippo pathway as a barrier to reprogramming. Hum Mol Genet. 2012; 21:2054-67. https://doi.org/10.1093/hmg/dds023.

52. Utikal J, Polo JM, Stadtfeld M, Maherali N, Kulalert W, Walsh RM, Khalil A, Rheinwald JG, Hochedlinger K. Immortalization eliminates a roadblock during cellular reprogramming into iPS cells. Nature. 2009; 460:1145-48. https://doi.org/10.1038/nature08285.

53. Menendez JA, Vellon L, Oliveras-Ferraros C, Cufí S, Vazquez-Martin A. mTOR-regulated senescence and autophagy during reprogramming of somatic cells to pluripotency: a roadmap from energy metabolism to stem cell renewal and aging. Cell Cycle. 2011; 10:3658-77. https://doi.org/10.4161/cc.10.21.18128.

54. Vazquez-Martin A, Vellon L, Quirós PM, Cufí S, Ruiz de Galarreta E, Oliveras-Ferraros C, Martin AG, Martin-Castillo B, López-Otín C, Menendez JA. Activation of AMP-activated protein kinase (AMPK) provides a metabolic barrier to reprogramming somatic cells into stem cells. Cell Cycle. 2012; 11:974-89. https://doi.org/10.4161/cc.11.5.19450.

55. Corbineau S, Lassalle B, Givelet M, Souissi-Sarahoui I, Firlej V, Romeo PH, Allemand I, Riou L, Fouchet P. Spermatogonial stem cells and progenitors are refractory to reprogramming to pluripotency by the transcription factors Oct3/4, c-Myc, Sox2 and Klf4. Oncotarget. 2017; 8:10050-63. https://doi.org/10.18632/oncotarget.14327.

56. Choong PF, Teh HX, Teoh HK, Ong HK, Choo KB, Sugii S, Cheong SK, Kamarul T. Heterogeneity of osteosarcoma cell lines led to variable responses in reprogramming. Int J Med Sci. 2014; 11:1154-60. https://doi.org/10.7150/ijms.8281.

57. Kim J, Hoffman JP, Alpaugh RK, Rhim AD, Reichert M, Stanger BZ, Furth EE, Sepulveda AR, Yuan CX, Won KJ, Donahue G, Sands J, Gumbs AA, Zaret KS. An iPSC line from human pancreatic ductal adenocarcinoma undergoes early to invasive stages of pancreatic cancer progression. Cell Reports. 2013; 3:2088-99. https://doi.org/10.1016/j.celrep.2013.05.036.

58. Choi SM, Liu H, Chaudhari P, Kim Y, Cheng L, Feng J, Sharkis S, Ye Z, Jang YY. Reprogramming of EBVimmortalized B-lymphocyte cell lines into induced pluripotent stem cells. Blood. 2011; 118:1801-05. https://doi.org/10.1182/blood-2011-03-340620.

59. Ichida JK, Tcw J, Williams LA, Carter AC, Shi Y, Moura MT, Ziller M, Singh S, Amabile G, Bock C, Umezawa A, Rubin LL, Bradner JE, et al. Notch inhibition allows oncogene- independent generation of iPS cells. Nat Chem Biol. 2014; 10:632-39. https://doi.org/10.1038/nchembio.1552.

60. Stricker S, Pollard S. Reprogramming cancer cells to pluripotency: an experimental tool for exploring cancer epigenetics. Epigenetics. 2014; 9:798-802. https://doi. org/10.4161/epi.28600.

61. Loh YH, Agarwal S, Park IH, Urbach A, Huo H, Heffner GC, Kim K, Miller JD, Ng K, Daley GQ. Generation of induced pluripotent stem cells from human blood. Blood. 2009; 113:5476-79. https://doi.org/10.1182/blood-2009-02-204800.

62. Wakao S, Kitada M, Dezawa M. The elite and stochastic model for iPS cell generation: multilineage-differentiating stress enduring (Muse) cells are readily reprogrammable into iPS cells. Cytometry A. 2013; 83:18-26. https://doi. org/10.1002/cyto.a.22069.

63. Papp B, Plath K. Reprogramming to pluripotency: stepwise resetting of the epigenetic landscape. Cell Res. 2011; 21:486-501. https://doi.org/10.1038/cr.2011.28.

64. Kumano K, Arai S, Kurokawa M. Generation of iPS cells from normal and malignant hematopoietic cells. Int J Hematol. 2013; 98:145-52. https://doi.org/10.1007/s12185-013-1385-x.

65. Stricker SH, Feber A, Engström PG, Carén H, Kurian KM, Takashima Y, Watts C, Way M, Dirks P, Bertone P, Smith A, Beck S, Pollard SM. Widespread resetting of DNA methylation in glioblastoma-initiating cells suppresses malignant cellular behavior in a lineage-dependent manner. Genes Dev. 2013; 27:654-69. https://doi.org/10.1101/ gad.212662.112.

66. Wiznerowicz M, Trono D. Conditional suppression of cellular genes: lentivirus vector-mediated drug-inducible RNA interference. J Virol. 2003; 77:8957-61. https://doi. org/10.1128/JVI.77.16.8957-8951.2003.

67. Somers A, Jean JC, Sommer CA, Omari A, Ford CC, Mills JA, Ying L, Sommer AG, Jean JM, Smith BW, Lafyatis R, Demierre MF, Weiss DJ, et al. Generation of transgene-free lung disease-specific human induced pluripotent stem cells using a single excisable lentiviral stem cell cassette. Stem Cells. 2010; 28:1728-40. https://doi.org/10.1002/stem.495.

68. Tang Y, Garson K, Li L, Vanderhyden BC. Optimization of lentiviral vector production using polyethyleniminemediated transfection. Oncol Lett. 2015; 9:55-62. https://doi.org/10.3892/ol.2014.2684.

69. Kostina A, Bjork H, Ignatieva E, Irtyuga O, Uspensky V, Semenova D, Maleki S, Tomilin A, Moiseeva O, Franco-Cereceda A, Gordeev M, Faggian G, Kostareva A, et al. Notch, BMP and WNT/ $\beta$-catenin network is impaired in endothelial cells of the patients with thoracic aortic aneurysm. Atheroscler Suppl. 2018; 35:e6-13. https://doi.org/10.1016/j.atherosclerosissup.2018.08.002.

70. Malashicheva A, Kanzler B, Tolkunova E, Trono D, Tomilin A. Lentivirus as a tool for lineage-specific gene manipulations. Genesis. 2007; 45:456-59. https://doi.org/10.1002/dvg.20313. 